\title{
PROPAGAÇÃO DE Ligustrum sinense POR ESTAQUIA SEMILENHOSA
}

\section{CUTTING PROPAGATION OF Ligustrum sinense}

\author{
Claudine Maria DE BONA ${ }^{1}$ \\ Georg HÖGER FILHO² \\ Carolina Smanhotto Schuchovski AUGUSTO3 \\ Luiz Antonio BIASI ${ }^{4}$
}

\begin{abstract}
RESUMO
O objetivo deste trabalho foi observar a influência do número de folhas no enraizamento de estacas semilenhosas de Ligustro. Foram utilizadas estacas apicais coletadas no inverno, sem ramificações. O delineamento experimental foi inteiramente casualizado com quatro repetições e 15 estacas por parcela. Os tratamentos foram os seguintes: estaca sem folhas, com uma folha, com duas folhas, com três folhas e com quatro folhas. As estacas foram mantidas em casa de vegetação com nebulização intermitente em substrato de casca de arroz carbonizada. A hipótese é que a área foliar influencia o enraizamento do Ligustro. Todos os tratamentos apresentaram $100 \%$ de sobrevivência e taxa de enraizamento de no mínimo $85 \%$. Os menores resultados de porcentagem de enraizamento, número de raízes emitidas por estaca e número de brotos por estaca foram obtidos com estacas com quatro folhas, e os melhores resultados com estacas sem folhas. Conclui-se que a propagação por estaquia de Ligustro pode ser facilmente realizada nas condições acima descritas, com estacas sem folhas.
\end{abstract}

Palavras-chave: Ligustro, estaca, área foliar, enraizamento.

\begin{abstract}
The aim of this work was to observe the influence of number of leaves on rooting semi-hardwood cuttings of Ligustrum sinense Lour. There were used apical cuttings collected on winter, without branches. The statistic design was completely randomized with four replicates and 15 cuttings in each experimental unit. The treatments were: cuttings without leaves, with one leaf, with two leaves, with three leaves and with four leaves. The cuttings were placed in greenhouse with intermittent mist chamber in carbonized rice hulls substrate. The hypothesis is that the number of leaves influences the rooting of Ligustro. All the treatments had a survival rate of $100 \%$ and at least $85 \%$ of rooting. The lowest results of rooting percentage, number of root per cutting and number of shoots per cutting were obtained with cuttings with four leaves and the better one was with none leaves. The conclusion is that cutting propagation of Ligustro can be easily made on the above conditions, with cuttings without leaves.
\end{abstract}

Key-words: Ligustro, cutting propagation, foliar area, rooting.

\footnotetext{
${ }^{1}$ Engenheira Agrônoma, Mestre em Agronomia, Produção Vegetal, da UFPR.

${ }^{2}$ Engenheiro Agrônomo, Mestre em Agronomia, Produção Vegetal, da UFPR.

${ }^{3}$ Engenheira Agrônoma, mestranda do Curso de Pós-Graduação em Agronomia, Produção Vegetal, da UFPR.

${ }^{4}$ Engenheiro Agrônomo, Dr., Professor Adjunto, Departamento de Fitotecnia e Fitossanitarismo, Setor de Ciências Agrárias, UFPR. Caixa Postal 19061 CEP: 81.531-990. Curitiba - PR. E-mail: labiasi@agrarias.ufpr.br
} 


\section{INTRODUÇÃO}

O Ligustrum sinense, pertencente à família Oleaceae, é uma planta ornamental arbustiva muito vigorosa, com folhas ovais, lanceoladas, de cor verde escuro, flores brancas, pequenas, agrupadas em grandes panículas terminais, frutos pequenos e escuros. É muito utilizada na ornamentação de praças e parques, pela abundância de suas flores (FLINT, 1983; MOTTET, 1970), sendo propagada em hortos e viveiros, principalmente pela estaquia.

Este é, segundo Read e Yang (1991), um dos métodos de propagação mais utilizados na área de plantas ornamentais, pois permite a obtenção de grande quantidade de mudas em curto espaço de tempo, com a vantagem de eliminação do período de juvenilidade (HARTMANN et al., 1997), além da obtenção de uniformidade e qualidade nas mudas, pela possibilidade da escolha e clonagem de plantas matrizes produtivas e com boa sanidade.

Apesar da grande utilização desta planta, há poucos trabalhos publicados sobre a espécie, e não foram encontradas publicações sobre propagação vegetativa do Ligustro.

A presença de folhas e gemas é um dos fatores que segundo Hartmann et al. (1997) exercem grande estímulo à iniciação de raízes. Este efeito está relacionado à translocação de carboidratos para a base da estaca e produção de auxinas e outros co-fatores importantes para o enraizamento. Segundo Pardo (1995), folhas e gemas são responsáveis pela produção de auxinas encontradas naturalmente na planta e pela síntese de vitaminas como a piridoxina, precursora do ácido naftaleno acético.

O objetivo deste trabalho foi observar a influência do número de folhas sobre a porcentagem de enraizamento em estacas semilenhosas de Ligustro.

\section{METODOLOGIA}

O experimento foi instalado em 23/08/2000, no Departamento de Fitotecnia e Fitossanitarismo do Setor de Ciências Agrárias da Universidade Federal do Paraná, em Curitiba - PR.

As estacas foram mantidas em casa de vegetação com nebulização intermitente, com controle automático de rega de 30 em 30 minutos, sobre bancadas elevadas de $3,00 \mathrm{~m}$ de comprimento por 1,00 $\mathrm{m}$ de largura, com fundo telado, preenchidas com casca de arroz carbonizada.

Foram utilizadas estacas apicais semilenhosas de Ligustrum sinense Lour, coletadas de plantas matrizes sadias, provenientes do Horto Municipal do Guabirotuba, em Curitiba - PR.

A coleta foi realizada no final do inverno, por ser o período em que a planta está fisiologicamente e nutricionalmente adequada para o enraizamento das estacas, pois, segundo Fachinello et al. (1994) a mai- or quantidade de carboidratos existente nesta época do ano é um fator importante para aumentar a taxa de enraizamento das estacas, uma vez que a auxina requer uma fonte de carbono para a biossíntese de ácidos nucleicos e proteínas.

As estacas tinham aproximadamente $15 \mathrm{~cm}$ de comprimento e folhas completamente expandidas.

Os tratamentos testados foram os seguintes: T1 - Estaca sem folhas; T2 - Estaca com uma folha; T3 - Estaca com duas folhas; T4 - Estaca com três folhas e T5 - Estaca com quatro folhas.

O delineamento experimental usado foi o inteiramente casualizado, com quatro repetições e 15 estacas por parcela. A avaliação foi realizada 60 dias após a instalação do experimento, pelos seguintes parâmetros: porcentagem de sobrevivência das estacas, porcentagem de enraizamento, porcentagem de brotação, número de raízes primárias por estaca, número de brotações por estaca, porcentagem de retenção foliar e massa seca de raízes.

Os resultados obtidos nos experimentos foram submetidos ao teste de Bartlet a depois à análise de variância, não havendo necessidade de transformação de dados. As médias foram analisadas pelo teste de Tukey devido ao teste $f$ ser significativo. $O$ programa estatístico utilizado foi o MSTATC.

\section{RESULTADOS E DISCUSSÃO}

Todos os tratamentos apresentaram taxa de $100 \%$ de sobrevivência de estacas, sendo que os tratamentos sem folha (T1), com uma folha (T2), com duas folhas (T3) e com 3 folhas (T4) apresentaram maior porcentagem de enraizamento. $\mathrm{O}$ tratamento sem folha (T1) teve maior número de raízes por estaca e o com 4 folhas (T5) apresentou comportamento inverso. Apesar da importância da translocação de carboidratos das folhas no desenvolvimento de raízes, o fato da estaca sem folhas apresentar tão bom resultado pode ser vantajoso na estaquia da época em questão, por diminuir a desidratação, devido a diminuição da área foliar, possibilitando, inclusive, a não utilização da nebulização intermitente.

A Tabela 1 apresenta os resultados da influência da área foliar no enraizamento de estacas de Ligustro. O tratamento com quatro folhas por estaca apresentou a menor porcentagem de enraizamento $(85 \%)$, diferindo dos demais tratamentos, que apresentaram as melhores taxas de enraizamento, a partir de $95 \%$. No enraizamento de estacas semilenhosas de pessegueiro, Fachinello e Kersten (1981) não observaram a formação de raízes em estacas sem foIhas. Esse resultado foi semelhante ao encontrado por Meleti e Nagai (1992), no qual a presença de foIhas aumentou o enraizamento de estacas de sete espécies de maracujazeiro e as estacas sem folhas deterioraram-se facilmente antes de enraizar em experimentos efetuados em condições similares a este experimento com Ligustro. 
TABELA 1 - Avaliação do enraizamento, brotação, número de raízes e brotos por estaca, retenção foliar e massa seca das raízes emitidas por estaca de Ligustrum sinense, em função do número de folhas da estaca. Média de quatro repetições ${ }^{1}$. Curitiba -2000 .

\begin{tabular}{lcccccc}
\hline Tratamento & $\begin{array}{c}\text { Enraizamento } \\
(\%)\end{array}$ & Brotação (\%) & $\begin{array}{c}\text { Raízes/estaca } \\
\left(\mathrm{n}^{\circ}\right)\end{array}$ & $\begin{array}{c}\text { Brotos/estaca } \\
\left(\mathrm{n}^{\circ}\right)\end{array}$ & $\begin{array}{c}\text { Retenção } \\
\text { foliar }(\%)\end{array}$ & $\begin{array}{c}\text { Massa seca } \\
\text { de raízes }(\mathrm{g})\end{array}$ \\
\hline Sem folgas & $96,67^{\mathrm{a}}$ & $100,00^{\mathrm{a}}$ & $7,48^{\mathrm{a}}$ & $6,93^{\mathrm{a}}$ & - & $0,73^{\mathrm{a}}$ \\
1 folha & $100,00^{\mathrm{a}}$ & $100,00^{\mathrm{a}}$ & $6,42 \mathrm{~b}$ & $6,26^{\mathrm{a}}$ & $96,67^{\mathrm{a}}$ & $1,03^{\mathrm{a}}$ \\
2 folhas & $98,33^{\mathrm{a}}$ & $93,33^{\mathrm{a}}$ & $5,93 \mathrm{~b}$ & $5,82^{\mathrm{a}}$ & $88,33^{\mathrm{a}}$ & $1,23^{\mathrm{a}}$ \\
3 folhas & $95,00 \mathrm{ab}$ & $90,00^{\mathrm{a}}$ & $5,51 \mathrm{~b}$ & $5,36^{\mathrm{a}}$ & $82,78 \mathrm{ab}$ & $1,22^{\mathrm{a}}$ \\
4 folhas & $85,00 \mathrm{~b}$ & $95,00^{\mathrm{a}}$ & $4,30 \mathrm{c}$ & $3,43 \mathrm{~b}$ & $67,92 \mathrm{~b}$ & $1,12^{\mathrm{a}}$ \\
\hline C.V. & $5,51 \%$ & $5,01 \%$ & $8,08 \%$ & $14,69 \%$ & $10,42 \%$ & $23,33 \%$ \\
\hline
\end{tabular}

Com relação ao parâmetro de retenção foliar os tratamentos T2, T3 e T4 tiveram resultados similares, sendo significativamente superior ao T5, que exibiu um maior perda foliar. A porcentagem de retenção foliar acompanhou a mesma tendência da porcentagem de enraizamento. Enquanto a presença de foIhas é importante no enraizamento, a retenção de foIhas é mais uma conseqüência do enraizamento do que uma causa direta deste (HARTMANN et al., 1997).

No parâmetro de número de brotos por estaca, o pior resultado ocorreu no tratamento T5 ( quatro folhas), sendo equivalente nos demais.

No entanto, houve uma tendência de aumento tanto no número como na porcentagem de brotações inversamente proporcional à área foliar, contrariamente ao artigo de Biasi e De Bona (2000) onde o aumento da área fotossintética influenciou positivamente no comprimento de brotações de carqueja.

Não houve diferença significativa entre os tratamentos na variável massa seca de raízes.

Em relação ao número de raízes por estaca enraizada, o tratamento T1 foi superior aos demais tratamentos com uma média de 7,48 raízes por estaca. Os tratamentos com uma, duas ou três folhas não variaram entre si e o tratamento com quatro folhas apresentou o menor número de raízes por estaca. Este resultado significativamente inferior do tratamento com quatro folhas é contrário aos resultados obtidos por Biasi et al. (1997), onde o aumento da área foliar influenciou positivamente o número de raízes emitidas por estaca em porta-enxertos de videira mediante estaquia semilenhosa, da mesma maneira, contrasta com a citação de Assis e Teixeira (1998), onde o número de folhas tem influência, especialmente, na velocidade de enraizamento e no número de raízes formadas.

Os resultados obtidos no presente trabalho, onde as estacas com o maior número de folhas apresentaram a menor taxa de enraizamento, número de raízes por estaca, número de brotos por estaca e a menor retenção foliar, provavelmente devem-se ao fato de as estacas possuírem folhas totalmente ex- pandidas e maduras, já que foram coletadas no final do inverno, e pelo motivo das estacas com menor número de folhas acabarem brotando mais que as estacas com quatro folhas iniciais. Este estímulo maior à brotação pode ter sido causado justamente pela ausência ou inferior quantidade de folhas. A elevada taxa de folhas e brotos novos, grandes produtores de auxinas e outras substâncias (KRAMER e KOZLOWSKI, 1979) provavelmente foi o fator que favoreceu o maior enraizamento nos tratamento com zero a três folhas do que no tratamento com quatro folhas iniciais, por estas serem mais velhas. Além disto, segundo Kester, citado por Assis e Teixeira (1998), as folhas podem também ser fonte de compostos inibidores do enraizamento, principalmente em plantas lenhosas adultas. Nesse caso, a sua presença pode prejudicar o enraizamento. $E$ também porque, segundo Hartmann et al. (1997), a fotossíntese não é requisito obrigatório para a formação de raízes em estacas.

Muitos autores têm estudado esse fato, concluindo que, em muitas espécies, não é necessário nenhum estímulo ao enraizamento (PARDO, 1995). A espécie estudada possui bom potencial de formação de raízes, podendo, portanto, ser considerada de fácil enraizamento.

\section{CONCLUSÃO}

Devido a alta porcentagem de enraizamento e brotação, bem como maior número de raízes e brotos por estaca, recomenda-se para a propagação de Ligustro por estaquia semilenhosa, em substrato de casca de arroz carbonizada, a utilização de estacas sem folhas, pois para o período de final de inverno. A ausência de folhas nas estacas é vantajosa, diminuindo a desidratação, havendo a possibilidade, inclusive, de se dispensar o uso da nebulização intermitente. 
DE BONA, C.M. et al. Propagação de Ligustrum sinense por...

\section{REFERÊNCIAS}

1 ASSIS, T. F. de; TEIXEIRA, S. L. Enraizamento de plantas lenhosas. In: TORRES, A. C.; CALDAS, L. S.; BUSO, J. A. Cultura de tecidos e transformação genética de plantas. Brasília : EMBRAPA-SPI / EMBRAPA CNPH, 1998. v. 1. p. 261-296.

2 BIASI, L. A.; DE BONA, C. M. Propagação de carqueja (Baccharis trimera (Less.) A. P. de Candolle) por meio de estaquia. Revista Brasileira de Plantas Medicinais, Botucatu, v. 2, n. 2, p. 37-43, 2000.

3 BIASI, L. A.; POMMER, C. V.; PINO, P. A. G. S. Propagação de porta-enxertos de videira mediante estaquia semilenhosa. Bragantia, Campinas, v. 56, n. 2, p. 367-376, 1997.

4 DE BONA, C. M. Estaquia, calagem e sombreamento de carqueja. Curitiba, 2002. 80f. Dissertação (Mestrado em Agronomia, Produção Vegetal) - Setor de Ciências Agrárias, universidade Federal do Paraná.

5 FACHINELLO, J. C.; HOFFMANN, A.; NACHTIGAL, J. C.; KERSTEN, E.; FORTES, G. R. L. Propagação de plantas frutíferas de clima temperado. Pelotas: UFPEL, 1994. 179p.

6 FACHINELLO, J. C.; KERSTEN, E. Efeito do ácido indolbutírico na percentagem de estacas semilenhosas enraizadas de pessegueiro (Prunus persica (L.) Batsch.) cv. diamante, em condições de nebulização. Revista Brasileira de Fruticultura, v. 3, p. 49-50, 1981.

7 FLINT, H. L. Landscape plants for eastern North America. New York: John Wiley \& Sons, 1983. 677 p.

8 HARTMANN, H. T.; KESTER, D. E.; DAVIES JR., F. T.; GENEVE, R. L. Plant propagation: principles and practices. 6. ed. New Jersey: Prentice-Hall, 1997. 770 p.

9 KRAMER, P. J.; KOZLOWSKI, T. T. Physiology of woody plants. New York: Academic Press, 1979. $811 \mathrm{p}$.

10 MELETI, L. M. M.; NAGAI, V. Enraizamento de estacas de sete espécies de maracujazeiro (Passiflora spp.). Revista Brasileira de Fruticultura, Cruz das Almas, v. 14, n. 2, p. 163-168, 1992.

11 MOTTET, S. Arboles y arbustos ornamentales. Madrid: Ediciones Mundi-Prensa, 1970. 300 p.

12 PARDO, V. A. Estaquia de marcela Achyrocline saturei oides (Lam.) D. C. sob diferentes períodos de enraizamento e doses de ácido indolbutírico. Porto Alegre, 1995. 67 f. Dissertação (Mestrado em Fitotecnia) - Faculdade de Agronomia da Universidade Federal do Rio Grande do Sul.

13 READ, P. E.; YANG, G. Plant growth regulator effects on rooting of forced softwood cuttings. Acta Horticulturae, v. 300, p. 197-200, 1991.

Recebido em 23/03/2001

Aceito em 10/12/2002 